\title{
THE HIGH SCHOOL LANGUAGE LABORATORY AS THE SUPERVISOR SEES IT
}

Ralph W. Bassett

As I consider again the title given to the remarks I am to make today, I am strongly tempted to take refuge in scripture - to tell you, quite simply, that the high school language laboratory, as the supervisor sees it, is "through a glass, darkly." I could then sit down, you could go to lunch, and we should all perhaps have had sufficient enlightenment. There are certainly many days when that phrase of St. Paul's seems to me to cover the situation more adequately than any other. But if I do not give way to the temptation, it is partly from a sense of obligation, and partly in the hope that the laboratory as I see, or as I tell it, may hold some interest for you.

I have wondered what there might be, in my experience, that would be of use to you in your own work. I certainly would not presume to speak to this audience on technical matters. Decibels and feedback are your business, not mine. Nor do I hold much that there is one sacred language-laboratory doctrine that I must expound. I am, I hope, much more modest than that. Let us say that I venture to hope that something of my views and my experience may - either by confirming or by contradicting your own, - comfort you if you are troubled, or help to support your ego, if that is its need.

Your program refers to "the high school language laboratory" as if it were an infinitely reduplicated identicle entity, and as if the foreign language supervisor had some cosmic vision which permitted him to take in at a glance this infinity of identical facilities. But I am the supervisor in this case, and I have, unfortunately, no cosmic vision. The number of laboratories I see is quite finite, and these discrete elements are by no means identical. I do beg your pardon for burdening you now with local history, but I must give you some information, at least, about the laboratories on which I base my observations. It would not, I submit, be entirely honest to talk to you in more general terms - to serve up as observed fact what is in reality based on the operation of language laboratories of a single school system as I see them.

About eighteen or nineteen years ago, as a high-school teacher of foreign language, I heard that the school district had purchased (wonder of wonders!) a wire recorder. Here at last, I thought, was the chance to do something positive about one of my objectives - the one many of us had despaired of accomplishing: to teach our students 


\section{High School Labs}

really to use the spoken word! I remember with what enthusiasm I set up that formidable instrument in the classroom, with what fear and trembling, after much urging, my students spoke into it, how we waited axiously to hear what had been said - only to find that, with ignorant ease, I had erased everything that had been recorded.

Wire gave way to tape, and our hopes were still high. My early years as supervisor included much urging of foreign language teachers to make use of the tape recorders that were being made available to them in increasing numbers in the district. Teachers were interested, as I had been. They were, it is true, worried about placing what looked like very expensive equipment in the hands of adolescents, and even more worried that they themselves might be responsible for damage to it. Still, they did their best. But they, and I, had too little imagination about where to go or what to do with this marvelous contraption, and it remained little more than a toy. Interesting, novel, and startling, but not, in reality, a part of the instructional program.

What was necessary, of course, was radically different ideas about the attainable objectives of foreign language instruction, and the methods to be used to pursue them. Such ideas did begin to become more widespread. In Portland, encouraged by the statements of Ed Cornelius, 1 in his two little books, I wrote into the official 1956 guide for the language teachers of the school district2 that the aims of the foreign language program were "understanding, speaking, grammar, reading, and writing", in that order, the now commonplace four-part objective - with a cautious nod to traditional teachers thrown in. Even with this sop, I submitted the statement to Portland's teachers with apprehension, but, to my surprise, received no criticism, not even from the most censervative. I mentioned the matter to one, thinking she had not even read the statement. But she was comforting. "That's all right," she said, "I know you have to write that kind of thing. I will just go on teaching as I have taught." As indeed she did.

In a way, she was typical, though more frank than the rest. The proposed sequence of instruction was calmly enough received, whether from a desire not to offend, or as a desire not to be thought old fashioned. Actual change in the classroom was another matter. Even those of us who accepted the aims expressed were vague about what methods we should use to take advantage of the equipment we were beginning to see about us, and new materials were nonexistent. So, in Portland as elsewhere, our installation of foreign language laboratories

'Edwin T. Cornelius, Jr., Language Teaching; a Guide for Teachers of Foreign Languages, Thomas Y. Crowell Company (New York, 1953).

2Edwin T'. Cornelius, Jr., How to Learn a Foreign Language, Thomas Y. Crowell Company (New York, 1955). 
did not really begin until about 1960 , when funds were made available through the NDEA, and teachers who had attended institutions came back with some idea of how to pursue their new and golden objectives.

In Portland, I recommended that we go into laboratory building rather slowly. I had two main reasons, I think, for not asking for the immediate expenditure for each school of the total sums which might conceivably have been made at that time. One was the profession's uncertainty about the use and the effectiveness of language laboratories, with the consequent possibility that they might well stand gathering dust waiting for teachers to decide to use them. On the other hand, it seemed likely that the early equipment available might very soon become obsolete, as language laboratory use spread throughout the nation. I was aware that funds might dry up, or the funds available might be diverted to other fields. I was not optimistic that the push for foreign language learning would necessarily last. I was aware, too, that, as easy as it might be to get the first laboratories built, it might well become difficult to persuade the school district to budget for them in every school. I also took cognizance of the fact that whatever equip. ment we once installed would remain for an indefinite period, even though superior equipment became available on the market and the original equipment had had sufficient use to justify its replacement. It is often easier, as I am sure you know, to obtain funds for a revolutionary new program than it is to obtain funds to maintain properly a stable program that has proved itself.

Because I have been talking about my own reflections, I have used the pronoun "I". In a district of this size, no one person ever carries the whole burden. What wc have today in Portland reflects the thinking of many: teachers, administrators, and even pupils, as well as the supervisor. But the progress has often, perhaps for that reason, been confused. I should certainly like to mention, in passing, the aid that the addition of a supervisor of Instructional Materials in the district has given. With my colleague Dr. Gilkey to take supervision of technical matters, I am freed to give my attention to what instructional aims we may wish to have technically assisted. Some of our first purchases are still in use in schools. We are not happy with all the equipment we now have, nor, in some places, do we have enough. But with our present administrative division of labor, we are, co. operatively now drawing up a plan which will supply each of our high schools with the best types of language laboratory equipment that we think we can profitably use.

In most of our thirteen high schools, at least one classroom, and in several schools more than one classroom, is equipped with a console that permits monitoring and communication with students as they follow a lesson. With each console we supply about thirty pairs of head-sets with activated microphones. The connecting wires run 


\section{High School Labs}

through pipes suspended from the ceiling, with considerable efficiency but with an aesthetic effect which is at best deplorable. The consoles generally have provided three lesson sources: two tape recorders and a record player. In actual fact, the record player is little used as a direct means of presentation; the space would be better used for an additional tape deck. You will note that this type of laboratory does not include a booth for the student. He picks up the headset from overhead and sits at his regular place, usually a tablet arm chair. Note, too, that it provides extremely limited facilities for recording. What we have here sometimes goes under the grandiose title of "electronic classroom". But in three schools there is a central laboratory serving all classes, with the number of positions varying from thirty to fifty. This arrangement, of course, necessitates the movement of students to the laboratory and away from the classroom. In two of these schools a laboratory technician is on duty, and is responsible for the maintenance of the equipment and the tapes and the general operation of the lab. In one other high school we have installed "EFI3 equipment: wireless transmission within the room and heard by the students through a miniature receiving set worn as part of the headset. This system does not provide for monitoring from a console; the instructor walks about the room to listen to students individually. So we have, essentially, three different types of arrangement. And in addition (what a change from wire-recorder days!) that almost universal electronic extension of the teacher's capacity: the tape recorder. These will be found in almost every foreign language classroom in the district. I am sure most teachers would agree that the recorder is the one thing that a teacher cannot do without.

Well, so much for the present state of affairs. With this picture of the sort of equipment that the 75 or more foreign language teachers in the Portland high school have at their disposal, I should like to move on to some comments on the laboratory idea and how it looks to me as a supervisor as I think of instruction and the results of instruction now and twenty years ago.

I am convinced of one thing, and that is that the avowed attempt to lead students to some degree of mastery of the spoken language, to some degree of ease of communication with a native face to face, is being reached to an infinitely greater degree today than was the case in the old days. It is true that in 1949 we had our " $A$ " students, even in ability to speak, as well as those who failed. The results obtained with the $\mathrm{A}$, the $\mathrm{B}$, the $\mathrm{C}$ students were often good, and sometimes superb, but excellence was generally to be observed only in reading and writing. Almost without exception students were terrified

3EFI: Electronic Futures, Inc, 57 Dodge Avenue, North Haven, Connecticut. Manufacturer. 
at the thought of saying anything more complicated than "good morning" in the language they were studying. That is not the case today. I do not mean that today's D's and F's necessarily go very far, although even they can say, "Good morning". But the A's, and B's, and C's do manage, with varying degrees of accuracy, to speak without fear in the language they are studying. It would be entirely proper for me to say that our students are now "masters" of the language. I do not look for that millennium for all our students regardless of what the electronic technologist may offer us. But in the later years of study, in particular, students appear to me - as I visit classes - to be able to express quite clearly what they wish to say.

But here we come to our apparently insoluble problem: what is responsible for the improvement in this respect? Is it the presence of the language laboratory? Is it the use of the language laboratory? Is it the tape recorder in the classroom? Is it the teacher? Is it the teacher's newer methods of presentation? Is it the text materials that have been developed and used? Is it the visual materials we have added? Is it, for that matter, a greater community feeling of worth that is communicated to students undertaking the study of foreign language? With this many variables, it is impossible to say categorically exactly what the contribution of each of these factors is. Some of these I have mentioned have abvious importance. I reject the idea that teachers are different as individuals, for we see students able to speak adequately coming from the classes of teachers who taught under the old conditions without the results they now obtain. But method is certainly part of the answer. Methods of all teachers, even the most reluctant, have been modified. Attendance at NDEA institutes has most certainly had the impact which was envisioned when they were first established. Yet it would be difficult, if not impossible, to find teachers pursuing any of the various orthodoxies that have from time to time been decreed by the theoreticians. The length of the prereading period may be taken as an example. At one time, there were those who advocated one hundred hours with the spoken language before written forms were to be introduced. This dogma was never adhered to in Portland, and certainly is not remotely approached at the present time. But the thesis at the basis of the recommendation does influence present instruction. By and large, the primacy of speech is recognized.

Along with the foreign language institute, credit for change in outcome must also go to the materials we use, or prescribe to be used. Yet I know of no teacher who uses the text of one publisher to the exclusion of any supplementary material from other sources. We can scarcely, therefore, give full credit for change to the materials.

As for the language laboratory, including the tape recorder in the classroom, before we can bestow upon these devices extensive - to say 


\section{High School Labs}

nothing of exclusive - credit, we should first have to sort out the myriad different ways in which our teachers make use of the electronic equipment they possess.

I must admit, then, to being unable to tell you positively that any particular combination of equipment, method, and material is Portland practice. I can tell you, however, that Portland foreign language teachers consider the language laboratory worth having and keeping. I shall return to what they have to say about them later. Let me treat for a moment the unflattering (unflattering to you, the language laboratory directors, that is) - the unflattering question being put, in several quarters, in one form or another. It is, "Shouldn't you people be looking for other jobs?"

In my opinion it is a question which can only have a negative answer, but it is not a frivolous question. Protests and doubts are expressed chiefly by those who say that the basic linguistic and psychological assumption on which our present methods are based, and hence our language laboratory work, is without merit. Obviously if there is at bottom an error in judgment as to how foreign language is best learned, and if our use of electronic devices is shown to rest upon a false foundation, then in all honesty and fairness we must report that matter to our employers. While the Portland Public Schools, for instance, have not spent on this type of instruction any sums approaching those that have been expended in fields such as physical education, science, and music, still no expenditure is justified unless we have some good reason to believe it will do what we want to have done. Who, then, is telling us that it will not? At the recent meeting here in Portland of the Pacific Northwest Conference on Foreign Languages, 4 Professor William Bull appeared to be saying just that. His view is that the most valuable practice in the study of foreign language is that spent to acquire comprehension of the structure of the language. Rote memorization, whether done in the traditional verb conjugations or in pattern sentences repeated on tape, are without any great importance. Professor Bull referred to the work of Wilga Rivers and her book, "The Psychologist and the Foreign Language Teacher".s What does Dr. Rivers have to say at the conclusion of the volume cited? On page 163 , we read:

"Keating's report on the effectiveness of language laboratories has brought out the fact that a good foreign language teacher without a

4The twentieth annual meeting of the Pacific Northwest Conference on Foreign Languages was held at the Sheraton Motor Inn, Portland, Oregon, April 11-12, 1969. The sponsoring institution was Lewis and Clark College, Portland; Manuel J. Macias, general chairman.

'Wilga M. Rivers, The Psychologist and the Foreign Language Teacher, University of Chicago Press (Chicago, 1964). 
language laboratory is able to achieve better results with students than a teacher who has the help of a laboratory, especially after the first year."6

If we go no further than this and if we accept without criticism the Keating report, ${ }^{7}$ you people would indeed seem to be practicing fraud. The language laboratory is not helping us. It should be junked, and along with it the language laboratory director. But let me counsel you to read, too, the twenty some lines which follow my previous quotation. Dr. Rivers goes on to say, "This is perhaps not so much criticism of the use of language laboratories as such as an indication of the widespread misuse of them by untrained teachers unsure of how to integrate the work of the laboratory into the general language program."8 We are here within a few sentences of the end of Dr. River's book, but what we have met is not a condemnation of the language laboratory, but a quarrel over method. I agree most heartily with Dr. Rivers, if it is her conclusion as it is mine, that language laboratories are often misused. And where they are misused, complaints about them are groundless.

The foreign language laboratory carnot be what it is not. Consider your automobile if you will. It stands outside your door. To get into it, leaving the driver's seat vacant, and yet complain because you arrive nowhere is surely a sign of madness. But we are not without instances of the same naive assumption among administrators, and, alas, even among foreign-language teachers. I well remember the discussions held with the principal of the school where we were making one of our early installations. He was delighted to learn that such electronic equipment would be placed in his school. It gave a certain cachet, a seal of approval, to his establishment as being up to date, but particularly he was happy because, he said, the foreign-language teacher could then be relieved for other teaching duties. When I protested that I did not see it quite in that light, he was astonished. He had assumed that he would have practically no further use for language teachers at all. Students would go in, press the button, and learn. Now I am not unaware that something like this is on the boards with certain programmed learning courses, and I am ready to admit that much of the time teachers have habitually spent in one activity or another may be fruitfully diverted to something quite different. But this to my mind is not the same as dismissing the teacher entirely. Less excusable, and equally bad, is the teacher who sends his students to the language laboratory regularly, but without preparation

Glbid., p. 163.

'Raymond Keating, A Study of the Effectiveness of Language Laboratories, Institute of Administrative Research, Teachers College, Columbia University (New York, 1963).

8Rivers, loc. cit. 


\section{High School Labs}

for what they are to do there, or understanding of what they may expect to accomplish. Motivation, response, stimulus-reward, all of these commonplaces of the psycholcgist are present and operative in language learning. Our highly motivated students are often able to postpone reward for a considerable length of time and in the face of considerable difficulties. But when we put exercises in a foreign language, on tape, offering as reward only the verifying response that follows the initial presentation of the material, we have built in some untenable assumptions. For one thing, we assume that the student is at a point where he can distinguish a defective reproduction of the model from an accurate one. "Correct pronunciation depends on the individual's ability to monitor the accuracy of his own response," say Politzer and Weiss.9 But we also, often unreasonably, assume that he has a desire to compare his response and the model. As I view school children, neither correct comparison nor the desire to compare is to be arrived at simply by sending a pupil to a laboratory. The only type of use of a foreign language laboratory that may have some chance of producing the improvement in mastery of form and structure and pronunciation that we desire must involve preparation in the classroom for the work that is to go on in the laboratory. The labora. tory experience must be checked, evaluated, and rewarded after the pupil returns to the classroom. I have a very strong feeling that those teachers who have expressed to me a dislike of language laboratories and who express the feeling that the results are not worth the trouble have, in general, made no such preparation. In other words, they have taught their students nothing before they go to the laboratory and they have provided no reward for careful laboratory work.

Now, what a student does in the language laboratory may be considered as homework or as class work. If it is to be called class work, the teacher must be on hand, must monitor the students' responses, must give the support, encouragement, and correction as it is needed while the practice goes on. If it is, as I believe it is in most colleges, homework, then the material that is to be practiced must be taught before it is practiced. There is no other way that I can see to guard against careless learning, or no learning. I see no point to inaccurate repetition, nor to vacant-minded sitting in the booth with headset on and tape running, while the student finishes his letter home.

I am rather skeptical by nature. I know that the language laboratory may be to the principal only the badge of a modern language department. I know that enthusiasts may easily claim more for laboratory work than can be accomplished. On the other hand, I see nothing

${ }^{9}$ Robert L. Politzer and Louis Weiss, "Developmental Aspects of Auditory Discrimination, Echo Response and Recall," Modern Language Journal, VOL. LIII, No. 2 (1969) p. 76. 
to indicate-certainly not in the absence of sound research on the subject-nothing to make us fear that the hours spent in laboratory must be fruitless. Let me quote one last time from Dr. Rivers, continuing from where I left off before: "Be that as it may," she says, "it does support the general thesis of this book that language communication involves a relationship between individuals and not merely the memorization and repetition of phrases and the practicing of structures."10 Again, I agree. But I find in it no inconsistency with language laboratory practice. No ore listening to a tape and repeating drills as directed will ever feel that he is having a real-life conversation with a native speaker, it is true. On the other hand, there can be no satisfaction to either participant in the corversation if there has not been attention (and serious attention) given in advance to as many of the structures and phrases as one can forsee being needed. If I know only English, and my African friend only his native Urdu, the conversa. tion is not likely to be intellectually very stimulating to either of us. One of us at least must first engage in some study (even if abstract and dull) of the language of the other before we can expect social communication in any real sense.

If the research evidence to support some particular phase of language laboratory activity is not as strong as we would like, 11 there is certainly no evidence that I find at all convincing that would indicate that the building of the language laboratories has been a waste of money. Except insofar as we have failed, and think we have often failed in this respect, to persuade our teachers to use the lab as an aid to their teaching, as an extension of the teacher's power rather than as a substitute for it. To this degree only has there been waste. When we get our research I am confident that it will show that what must be done is what good teachers have done in the past-with whatever aids they had at their command-structure study and drill for habit formation; confrontation in social situations for meaningful application of what has been learned. The laboratory of the future will continue to include pattern drill. I find it difficult to believe that with all that can be said against memorization that it can be entirely eliminated. But let us not think we have a case of "either-or." I am not talking about a course made up exclusively of rote memorization, and I am equally sure that analysis alone will not produce results. We must labor to give our student an understanding of what he is doing, but we must also see to it that he has plenty of opportunity to apply what he has memorized and understood. Given enough money, we may even find it possible to bring something of the social situation which

${ }^{10}$ Rivers, loc. cit.

"See John B. Carroll: Memorandum: On needed research in the psycholinguistic aspects of language teaching. Foreign Language Annals: Vol. No. 3, pp. 236-238. 


\section{High School Labs}

makes language live to the laboratory. It has been done already through the use of films; it has been done to a degree with that type of equipment which simulates the telephone. We may even look to a greater number of programmed materials like those Mr. Cornelius's English Language Services prepared for the training of language teachers, with student response to a filmed situation. ${ }^{12}$ On the other hand, we may find that simulation of a social situation is too expensive to be worth adding to the laboratory set-up. Nevertheless, this is a field which deserves much more exploration than it has received up to this point. Whether there is included in the laboratory of the future direct-wire television, or films, or other visuals, a laboratory recog. nizably similar to the ones we now know must remain.

I have given you some-not too much, I hope-of the background of Portland language laboratory use. I have mentioned what I see, in instructional terms. What I see, naturally, is also based on the reactions of our teachers: those in whose hands, after all, the fate of the language laboratory director rests. I should like to summarize what Portland teachers, in my opinion, would generally agree upon, and read you their most recent recommendations.

In the opinion of the Portland staff:

Languare laboratories are effective teaching aids at any level of language study, but have their greatest use with the first two years.

During these first two years, material to be practiced in the laboratory must be anticipated in classroom preparation. The amount of classroom preparation will depend on the kind of laboratory activity to be engaged in.

Most of them believe that about one-half a student's time should be spent listening. Listening time will increase, and speaking decrease, as the student progresses through the third, fourth, and fifth years of instruction.

They think that no more than about one quarter of a student's time should be spent in recording and listening to recorded responses.

They hold in relatively low esteem those materials which tend to isolate the learner, or which are not integrated with text materials, whether tapes, films, filmstrips, or records.

Opinion on the type of laboratory to be preferred is mixed, and apparently influenced greatly in favor of the type the individual teacher has known. While most would favor a rather complete laboratory, many prefer classrooms equipped for instant laboratory work, and there is still a by no means insignificant number who would willingly limit themselves to a tape recorder in the classroom.

About a year ago, the foreign-language department chairmen

12English Language Services, 1620 Belmont N. W. Washington, D. C. 
agreed on these recommendations, which I take the liberty of reading to you:

1. Each foreign-language teacher should have available in his classroom at all times a tape recorder of high fidelity.

2. In each high school at least one foreign language classroom should be equipped with high quality headsets and microphones, suspended from the ceiling, for each student.

3. The same classroom should have a console that permits the teacher to listen to and to speak with each student individually, with the lesson automatically cut out as the exchange takes place. The console should provide a minimum of three lesson sources, and provision for recording responses of five or six students at one time.

4. Plans should be prepared to equip, within a five-year period, each high school, modern foreign-language classroom as described above.

5. Within the same period, each elementary school room used for foreign-language instruction should receive equipment permitting the use of individual headsets with activated microphone by from one to eight pupils at a time.

6. Schools organized as seventh-and eight-grade centers should be equipped as are the high schools.

Well, there you are-the language lab as I see it. We are far from knowing all the answers; we are far from having persuaded all teachers to make use of the best we know. But I do not apologize for our language laboratories, nor seek to grade them down. If any such idea entered my head, all I would have to do would be to recall that day with the wire recorder. We are beyond that, and not so many years have passed, after all.

About the Author: Mr. Bassett is Supervisor of Foreign Languages, Portland (Oregon) Public Schools. 